\title{
Ferulic Acid Esterase Activities of Typical Intestinal Bacteria
}

\author{
Chieko Nishizawa, ${ }^{1}$ Takeo OHTA, ${ }^{1,2 *}$ Yukari Egashira ${ }^{2}$ and Hiroo Sanada ${ }^{1,2}$ \\ ${ }^{1}$ Division of Production Science and Technology, Graduate School of Science and Technology, ${ }^{2}$ Department of Bioproduction \\ Science, Faculty of Horticulture, Chiba University, 648 Matsudo, Matsudo-shi 271, Japan
}

Received October 8, 1997; Accepted December 9, 1997

\begin{abstract}
Ferulic acid esterase activity arose in the ceca of rats that were fed on acid hydrolysate of refined corn bran. The main component of this hydrolysate was soluble ferulic acid arabinoxylan ester. In order to determine the relationship between the ferulic acid esterase activity and intestinal bacteria, the ferulic acid esterase activities from the four kinds of typical bacteria in the intestine were measured. Ferulic acid arabinose ester (LMW) and ferulic acid arabinoxylan ester (HMW) were used as substrates. The enzyme from Lactobacillus acidophilus exhibited the highest activity when LMW was used as a substrate. However, when HMW was used, all enzymes from these bacteria exhibited trace activities. At the same time, Bifidobacterium bifidum showed high xylanase and arabinofuranosidase activities. It was suggested that the xylanase and the arabinofuranosidase from bacteria such as $B$. bifidum attacked HMW and degraded it to lower molecules at first. The ferulic acid esterase from bacteria such as $L$. acidophilus might then act to release ferulic acid in the cecum.
\end{abstract}

Keywords: ferulic acid esterase, intestinal bacteria, Lactobacillus, Bifidobacterium

Many investigations on dietary fiber have been carried out, and evidence is emerging that dietary fiber has an influence on nutrition because it is fermented, absorbed and has various functions (Ebihara \& Kiriyama, 1990; Ayano, 1992). Cereals such as rice, wheat and corn, are the main suppliers of dietary fiber. Their structures have been studied in detail (Brilliouet et al., 1982; Shibuya, 1984; Kamisaka et al., 1990; Shiba et $a l ., 1992)$. It has become apparent that the corn bran cell wall mainly consists of ferulic acid arabinoxylan ester, that is, the component of decomposed corn bran is $O$-(5-O-feruloyl- $\alpha$ L-arabinofuranosyl $)-(1 \rightarrow 3)-O-\beta$-D-xylopyranosyl- $(1 \rightarrow 4)$-Dxylopyranose (Kato, 1992; Kato \& Nevins, 1985). On the other hand, soluble ferulic acid arabinoxylan ester was obtained by the hydrolysis of refined corn bran (RCB). This compound showed antioxidative activities against autoxidation of linoleic acid and lipid peroxidation of rat liver microsomal system induced by $\mathrm{CCl}_{4}$ (Ohta et al., 1994). This compound also showed antioxidative activities against LDL oxidation systems, and these antioxidant properties came from ferulic acid, which was present as ferulic acid arabinoxylan ester. Further, ferulic acid and ferulic acid arabinose ester were absorbed from the tract to the circulation system (Ohta et al., 1997).

Recently, ferulic acid esterases have been isolated from ruminant microorganisms, soil bacteria and fungi (MacKenzie \& Bilous, 1988; Borneman et al., 1992; Faulds \& Williamson, 1994). Ferulic acid esterases from human feces were also studied (Faulds \& Williamson, 1995; Kroon et al., 1996; 1997). These studies pointed out that ferulic acid esterase can solubilize ferulic acid from plant fiber and that the rate of solubilization of ferulic acid from insoluble plant cell walls depends on the plant sources.

\footnotetext{
* To whom correspondence should be addresed.
}

In a previous paper, we reported that serum cholesterol levels tended to be suppressed when rats were fed on the hydrolysate of RCB with high cholesterol diets. At the same time, ferulic acid esterase activity arose in the ceca of the rats. Further, xylanase, arabinofuranosidase and ferulic acid esterase might act synergistically in the cecum (Nishizawa et al., 1997).

The objective of this study was to measure ferulic acid esterase activities of typical bacteria which exist in the cecum (Aoe et al., 1988) in order to determine the relationship between the ferulic acid esterase activity and intestinal bacteria in the cecum. These activities were compared with that of the cecal contents of the rats.

\section{Materials and Methods}

Materials RCB was kindly provided by Nihon Shokuhin Kako Co., Ltd. (Shizuoka). All chemicals used in this experiments were of reagent grade.

Strains Lactobacillus acidophilus (IFO 13951T, L. acidophilus), Lactobacillus brevis (IFO 13110, L. brevis), Lactobacillus rhamnosus (IFO 14710, L. rhamnosus) and Bifidobacterium bifidum (IFO 14252T, B. bifidum) were obtained from the Institute For Fermentation, Osaka (IFO, Osaka). These strains were chosen from the strains that were entrusted to IFO. The cecal contents were obtained from the rats that were fed on the acid hydrolysate of RCB for 10 days. The main component of the hydrolysate was ferulic acid arabinoxylan ester (Nishizawa et al., 1997).

Cultivation A preculture of L. acidophilus was grown stationarily at $37^{\circ} \mathrm{C}$ for one night in medium ( $0.5 \%$ polypeptone, $0.5 \%$ yeast extract, $0.5 \%$ glucose, $0.2 \%$ lactose, $0.05 \%$ Tween $80,0.1 \% \mathrm{MgSO}_{4} \cdot 7 \mathrm{H}_{2} \mathrm{O}, \mathrm{pH} 6.6-7.0$ ). The culture was inoculated into the same medium and cultivated at $37^{\circ} \mathrm{C}$ for $48 \mathrm{~h}$ without aeration or agitation. L. brevis and L. rham- 
nosus were grown following the procedure used for $L$. acidophilus, but the medium contained $0.5 \%$ polypeptone, $0.5 \%$ yeast extract, $0.5 \%$ glucose and $0.1 \% \mathrm{MgSO}_{4} \cdot 7 \mathrm{H}_{2} \mathrm{O}(\mathrm{pH}$ 6.6-7.0). B. bifidum and the cecal contents of the rats were also cultivated anaerobically as the same as $L$. acidophilus, except that the medium contained 5.9\% GAM broth ( $\mathrm{pH} 7.3$ ) (Nissui, Tokyo). After the cultivation, the cells were collected by centrifugation ( $3000 \mathrm{rpm}, 10 \mathrm{~min}$ ), washed three times with $10 \mathrm{~mm}$ acetate buffer ( $\mathrm{pH} 5.0)$ to remove the culture medium and were stored at $-20^{\circ} \mathrm{C}$.

Enzyme preparations The cells were suspended in 10 $\mathrm{mM}$ acetate buffer ( $\mathrm{pH} 5.0)$ and were disrupted by sonification at $20 \mathrm{kHz}$ for $3 \mathrm{~min}$ ( $1 \mathrm{~min}, 3$ times). This solution was centrifuged (3000 rpm, $10 \mathrm{~min})$ and the supernatant was used for the measurements of enzymatic activities. Protein concentrations were estimated by the method described by Lowry (1951), using bovine albumin as the standard.

Preparation of substrates $\mathrm{RCB}(5 \mathrm{~g})$ was heated in 200 $\mathrm{ml}$ of $30 \mathrm{~mm}$ oxalic acid solution in a boiling water bath for $3 \mathrm{~h}$. After cooling in water, the insoluble fraction was removed by filtration and the filtrate was evaporated under reduced pressure. The hydrolysate was fractionated on Sephadex LH-20 (column dimensions, $15 \mathrm{~mm}$ i.d. $\times 200 \mathrm{~cm}$; solvent, $50 \mathrm{v} / \mathrm{v} \%$ aqueous methanol). The absorbance at 320 $\mathrm{nm}$ of each fraction was measured (Shimadzu UV-1200 UV-VIS spectrophotometer). Figure 1 shows the results of gel filtration. Fraction A is ferulic acid arabinoxylan ester (high molecular weight fraction, HMW), and fraction B is ferulic acid arabinose ester (low molecular weight fraction, LMW), which were identified by TLC and NMR analyses (Ohta $e t$ al., 1994). These fractions were collected, evaporated under reduced pressure and dissolved in $10 \mathrm{mM}$ acetate buffer $(\mathrm{pH}$ 5.0). The concentration of the solution was also determined by measuring the absorbance at $320 \mathrm{~nm}$.

Enzyme assays

Ferulic acid esterase activity The enzyme solution $(0.2$ $\mathrm{ml}$ ) was mixed with a substrate in $10 \mathrm{~mm}$ acetate buffer $(\mathrm{pH}$ $5.0,0.1 \mathrm{ml}$ ) and incubated at $37^{\circ} \mathrm{C}$. After the incubation, the reaction mixtures were placed in a boiling water bath for 5 min. Following centrifugation $(6500 \times g, 10 \mathrm{~min})$, the ferulic

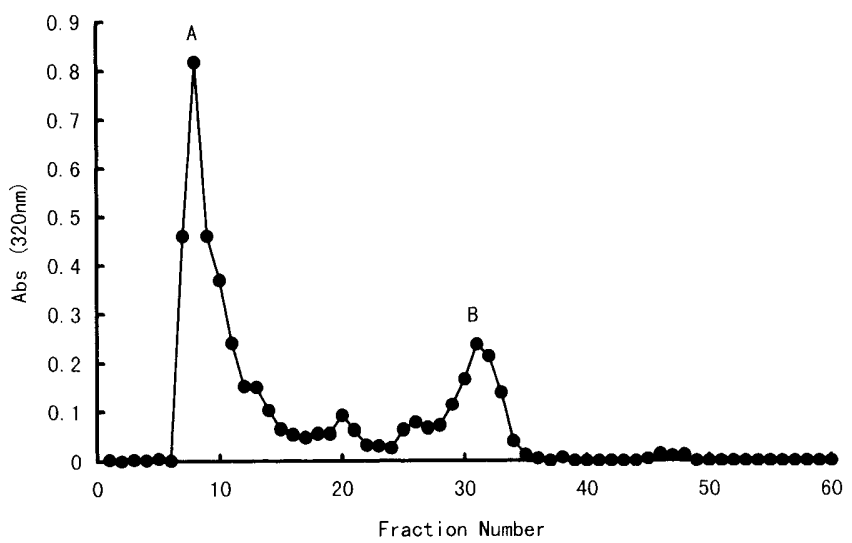

Fig. 1. Gel filtration chromatogram of RCB hydrolysate on Sephadex LH-20. Fraction A was a high molecular weight fraction (ferulic acid arabinoxylan ester, HMW), and fraction B was a low molecular weight fraction (ferulic acid arabinose ester, LMW). Measuring conditions were described in the text. acid concentration of the supernatant fractions was determined by high-performance liquid chromatography (Hitachi Model L-6200) with a column ( $\mu$-Bondapak C18, $125 \AA$, 10 $\mu \mathrm{m}, 3.9 \times 300 \mathrm{~mm}$, Waters). The mobile phase was $50 \mathrm{v} / \mathrm{v} \%$ aqueous methanol and ran at a flow rate of $1 \mathrm{ml} / \mathrm{min}$. Ferulic acid was detected with a UV detector (Hitachi Model L-4200) set at $320 \mathrm{~nm}$ (Hatfield et al., 1991).

Xylanase activity The enzyme solution $(0.1 \mathrm{ml})$ was mixed with $1 \%$ oat spelts xylan (Sigma) in $10 \mathrm{~mm}$ acetate

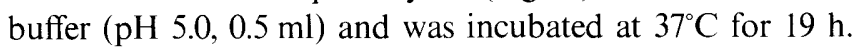
The liberated reducing sugar was determined according to the Somogyi-Nelson method (Somogyi, 1952; Nelson, 1944). Xylose was used as the standard.

Arabinofuranosidase activity The enzyme solution (0.1 ml) was mixed with $0.1 \% p$-nitrophenyl- $\alpha$-L-arabinofuranoside (Sigma) in $10 \mathrm{~mm}$ acetate buffer (pH 5.0, $0.2 \mathrm{ml})$ and was incubated at $37^{\circ} \mathrm{C}$ for $19 \mathrm{~h}$. The reaction was terminated by the addition of $1 \% \mathrm{Na}_{2} \mathrm{CO}_{3}$ solution $(1 \mathrm{ml})$. The liberated $p$-nitrophenol was measured by the absorption of $420 \mathrm{~nm}$.

\section{Results}

Ferulic acid esterase activity Ferulic acid esterase activities of bacteria are shown in Table 1. When the substrate was LMW, the enzyme from $L$. acidophilus exhibited the highest activity. The enzymes from other bacteria showed lower activities or only trace activities. When the substrate was HMW, the enzymatic activities were traces.

Xylanase activity and arabinofuranosidase activity Table 2 shows xylanase and arabinofuranosidase activities of bacteria. Only the enzymes from $B$. bifidum and the cecum contents exhibited xylanase activity, and the enzyme from $B$. bifidum showed higher activity than that of the cecum contents. The enzymes from the cecum contents and $B$. bifidum exhibited arabinofuranosidase activity, and the

Table 1. Ferulic acid esterase activity ( $\mu$ mole ferulic acid/mg protein).

\begin{tabular}{lcc}
\hline Bacteria & LMW & HMW \\
\hline L. acidophilus & 21.4 & trace \\
L. brevis & 0.50 & trace \\
L. rhamnosus & trace & trace \\
B. bifidum & trace & trace \\
Cecum contents & 0.96 & trace \\
\hline
\end{tabular}

Ferulic acid esterase activity was measured after $19-\mathrm{h}$ incubation at $37^{\circ} \mathrm{C}$. Substrates were LMW and HMW. Data are mean values $(n=2)$. "trace" means that the activity was less than $0.2 \mu$ mole ferulic acid $/ \mathrm{mg}$ protein.

Table 2. Xylanase activity and arabinofuranosidase activity.

\begin{tabular}{lcc}
\hline Bacteria & $\begin{array}{c}\text { Xylanase activity } \\
(\mu \text { mole xylose } / \mathrm{mg} \\
\text { protein })\end{array}$ & $\begin{array}{c}\text { Arabinofuranosidase activity } \\
(\mu \text { mole } p \text {-nitrophenol } / \mathrm{mg} \\
\text { protein })\end{array}$ \\
\hline L. acidophilus & $\mathrm{ND}$ & trace \\
L. brevis & $\mathrm{ND}$ & trace \\
L. rhamnosus & $\mathrm{ND}$ & trace \\
B. bifidum & 6.60 & 1.28 \\
Cecum contents & 0.19 & 3.18 \\
\hline
\end{tabular}

The enzymatic activity was measured after 19-h incubation as described in the text. Data are the mean values $(n=3)$. "ND" means not detected and "trace" means the activity was less than $0.5 \mu \mathrm{mole} / \mathrm{mg}$ protein. 


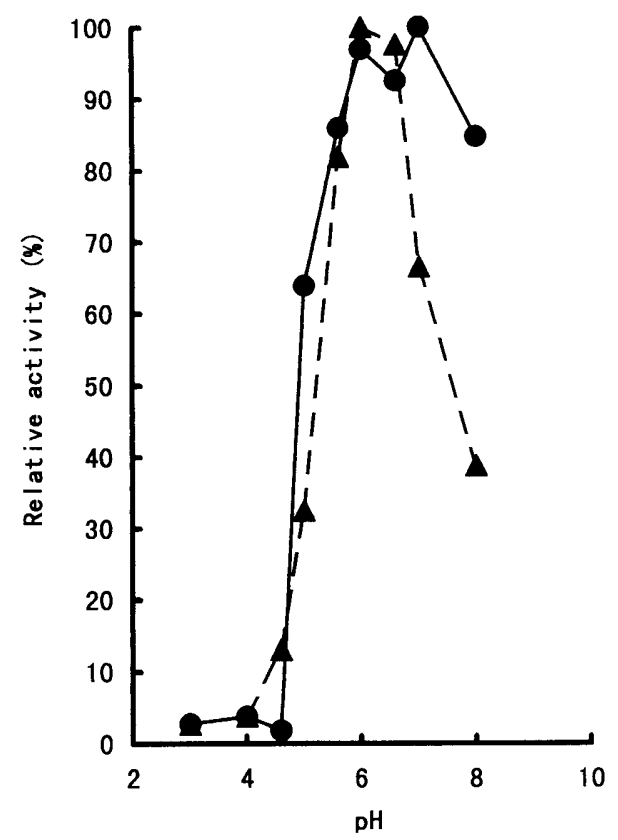

Fig. 2. Effect of $\mathrm{pH}$ on ferulic acid esterase activity. The enzyme solution $(0.2$ $\mathrm{ml}$ ) was mixed with $0.1 \mathrm{ml}$ of LMW solution and $0.5 \mathrm{ml} \mathrm{Mcllvaine} \mathrm{buffer} \mathrm{and}$ was incubated at various pHs at $37^{\circ} \mathrm{C}$ as described in the text. Incubation times were $3 \mathrm{~h}$ and $1 \mathrm{~h}$ for enzymes from the cecum contents and L. acidophilus, respectively. $\bullet$, cecum contents; $\boldsymbol{\Delta}, L$. acidophilus.

enzyme from the cecum contents showed higher activity than that of B. bifidum.

Effect of $\mathrm{pH}$ and temperature on ferulic acid esterase activity Ferulic acid esterase activity from $L$. acidophilus and the cecum contents were measured using McIlvaine buffer at various pHs. Figure 2 shows the effect of $\mathrm{pH}$ on ferulic acid esterase activity. The optimum $\mathrm{pH}$ was observed from 6.0 to 6.6 in the enzyme from L. acidophilus. The enzyme from the cecum contents showed the same tendency, but this range was slightly wider than that of $L$. acidophilus.

Figure 3 shows the effect of temperature when the enzymes from $L$. acidophilus and the cecum contents were incubated in Mcllvaine buffer at $\mathrm{pH}$ 6.0. The optimum temperature was from $37^{\circ} \mathrm{C}$ to $45^{\circ} \mathrm{C}$ in the enzyme from $L$. acidophilus and from $30^{\circ} \mathrm{C}$ to $45^{\circ} \mathrm{C}$ in that of the cecum contents. The range observed in the cecum contents was slightly wider than that of L. acidophilus. The optimum temperature ranges of these enzymes almost overlapped, but the enzyme from the cecum had a wider ranges than that of $L$. acidophilus.

\section{Discussion}

L. acidophilus, L. brevis, L. rhamnosus and B. bifidum were typical bacteria in intestine (Mitsuoka, 1995). Aoe et al . (1988) reported that Lactobacillus and Bifidobacterium existed in the feces of rats after the prebreeding, and the number of Bifidobacterium increased significantly when the rats were fed on hemicellulose from rice bran. The rats used in this experiment were the same strain (Sprague-Dawley) male rats as in the experiment of Aoe et al., and the main component of dietary fiber was similar, that is, the main component of hemicellulose from rice bran was arabinoxylan

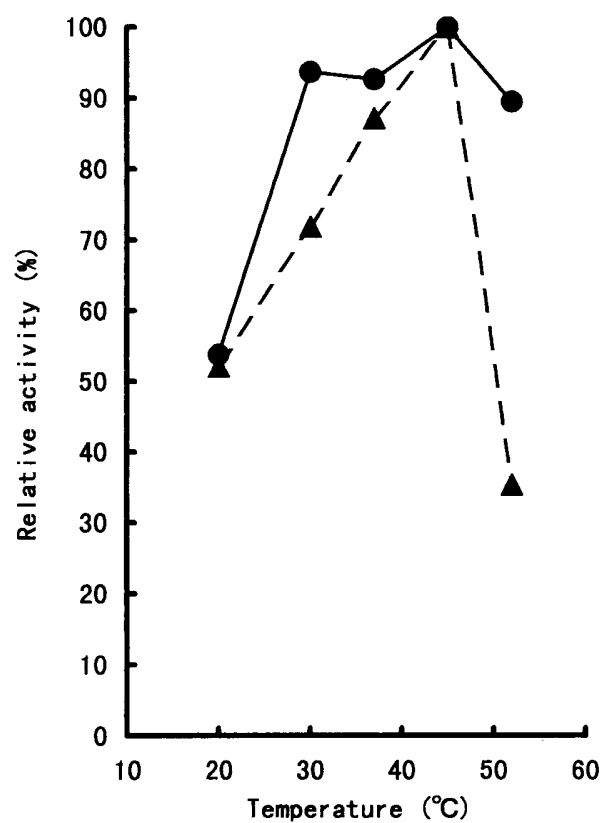

Fig. 3. Effect of temperature on ferulic acid esterase activity. The enzyme solution $(0.2 \mathrm{ml})$ was mixed with $0.1 \mathrm{ml}$ of $\mathrm{LMW}$ solution and $0.5 \mathrm{ml}$ McIlvaine buffer ( $\mathrm{pH} \mathrm{6.0)}$ and was incubated at various temperature as described in the text. Incubation times were $3 \mathrm{~h}$ and $1 \mathrm{~h}$ for enzymes from the cecum contents and $L$. acidophilus, respectively. $\bullet$, cecum contents; $\boldsymbol{\Delta}, L$. acidophilus

and that of the hydrolysate of RCB was ferulic acid arabinoxylan ester, in which $4 \mathrm{w} / \mathrm{w} \%$ ferulic acid was esterified to arabinoxylan. Therefore, Bifidobacterium and Lactobacillus were supposed to exist from the beginning of the experiment, and bacteria in the cecum changed as in the experiment of Aoe et al.

The ferulic acid esterase activities of these bacteria were measured and compared with that of the cecum contents of the rats. When LMW was used as a substrate, the enzyme from L. acidophilus exhibited the highest activity, but enzymes from other bacteria exhibited lower or trace esterase activities. This indicated that the ferulic acid esterase activity in the cecum was caused by bacteria such as $L$. acidophilus. All enzymes showed trace activities when HMW was used as a substrate. The remarkable difference between LMW and HMW was the size of the molecules. That is, as mentioned before, the main components of LMW and HMW were ferulic acid arabinose ester and ferulic acid arabinoxylan ester, respectively (Ohta et al., 1994). MacKenzie and Bilous (1988) studied the ferulic acid esterase activity from the fungus Schizophyllum commune and reported that the enhancement of ferulic acid esterase was due to the size or inaccessibility of the materials bearing the ferulic acid residue. In our experiment, the ferulic acid esterase could attack small molecules easier than large ones.

There are many species of bacteria in the cecum. One has a high xylanase activity and another has a high arabinofuranosidase activity. There are also bacteria that have a high ferulic acid esterase activity such as L. acidophilus. At first, the enzymes from bacteria, which have a high xylanase or arabinofuranosidase activity, might attack and degrade 
HMW to smaller molecules. Next, ferulic acid esterase from other bacteria might attack these smaller molecules and ferulic acid would be released. The enzymes from various kinds of bacteria might act synergistically in the cecum.

In order to obtain more details on this degrading mechanism, xylanase activity and arabinofuranosidase activity of enzymes from these bacteria were measured (Table 2). $B$. bifidum and the cecum contents exhibited both enzymatic activities, and enzymes from other bacteria either showed trace activities or none. There are many kinds of bacteria and the concentration of B. bifidum was diluted in the cecum. As a result, an enzyme from the cecal contents might exhibit lower xylanase activity than that of B. bifidum. However, in the case of arabinofuranosidase activity, there might be many kinds of bacteria that exhibited high arabinofuranosidase activity. For this reason, the arabinofuranosidase activity from the cecum contents became higher than that of $B$. bifidum. However, in this experiment, the concentration of $B$. bifidum in the cecum was not measured. This should be elucidated.

Figures 2 and 3 show the effects of $\mathrm{pH}$ and temperature on ferulic acid esterase activities of enzymes from $L$. acidophilus and the cecum contents. The optimum $\mathrm{pH}$ and temperature almost overlapped, that is, $\mathrm{pH} 6.0-7.0$ and $37-45^{\circ} \mathrm{C}$, respectively. However, the optimum ranges of $\mathrm{pH}$ and temperature of the enzyme from the cecum contents were wider than those of $L$. acidophilus. Many kinds of bacteria in the cecum might relate to these phenomena, and $L$. acidophilus might be one kind of relating bacterium. The $\mathrm{pH}$ in the cecum is acidic because dietary fiber is degraded by intestinal bacteria and short-chain fatty acids are produced. In addition, the temperature of the body is about $37^{\circ} \mathrm{C}$. It might be more effective for L. acidophilus to release ferulic acid in the cecum.

By the way, ferulic acid is well-known to have an antioxidant potential because it readily forms a resonance-stabilized phenoxy radical, and this radical has the ability to terminate free radical chain reactions (Graf, 1992). Furthermore, ferulic acid arabinoxylan ester has antioxidant activity against the autoxidation of linoleic acid and lipid peroxidation of rat liver microsomal system induced by $\mathrm{CCl}_{4}$ in vitro, and it is absorbed from the digestive tract into the vascular system (Ohta et al., 1994, 1997). The more the bacteria such as $L$. acidophilus and $B$. bifidum increase in the cecum, the more favorable this would be for the body.

The existence of ferulic acid esterase in typical intestinal bacteria was shown in this study, but whether ferulic acid esterase activity was induced in L. acidophilus or whether the number of $L$. acidophilus was increased in the cecum of the rat was not examined. This should be elucidated. Furthermore, this enzyme was not purified and characterized. Although the bacteria used in this experiment belong to the same species or related species, their enzymatic activities were different. It was not clear in this experiment that these differences came from the differences in species, cultivation methods or other cultivating conditions. They should be elucidated in the near future.

\section{References}

Aoe, S., Ohta, F. and Ayano, Y. (1988). Effect of water-soluble dietary fiber on intestinal microflora in rats. Eiyo Syokuryo Gakkaishi, 41, 203-211 (in Japanese)

Ayano, Y. (1992). Dietary fiber in cereals: Nutrition and physiological aspect. Nippon Eiyo Syokuryo Gakkaishi, 45, 209-219 (in Japanese).

Borneman W.C., Ljungdahl, L.G, Hartley, R.D. and Akin, D.E. (1992). Purification and partial characterization of two feruloyl esterases from the anaerobic fungus Neocallimastix strain MC-2. Appl. Environ. Microbiol., 58, 3762-3766.

Brillouet, J.M., Joseleau, J.P., Utille, J.P. and Lelièvre, D. (1982). Isolation, purification and characterization of a complex heteroxylan from industrial wheat bran. J. Agric. Food Chem., 30, 488-495.

Ebihara, K. and Kiriyama, S. (1990). Physico-chemical property and physiological functions of dietary fiber. Nippon Shokuhin Kogyo Gakkaishi, 37, 916-933 (in Japanese).

Faulds, C.B. and Williamson, G. (1994). Purification and characterization of a ferulic acid esterase (FAE-III) from Aspergillus niger: specificity for the phenolic moiety and binding to microcrystalline cellulose. Microbioligy, 140, 779-787.

Faulds, C.B. and Williamson, G. (1995). Release of the antioxidant, ferulic acid, from plant material by specific esterases. Biochem. Soc. Trans., 23, 253.

Graf, E. (1992). Antioxidant potential of ferulic acid. Free Radical Biol. Med., 13, 435-448.

Hatfield, R.D., Helm, R.F. and Ralph, J. (1991). Synthesis of methyl 5- $O$-trans-feruloyl- $\alpha$-L-arabinofuranoside and its use as a substrate to assess feruloyl esterase activity. Anal. Biochem., 194, 25-33.

Kamisaka, S., Takeda, S. and Shibata, K. (1990). Diferulic and ferulic acid in the cell wall of Avena coleoptiles-Their relationships to mechanical properties of the cell wall. Physiol. Plant., 78, 1-7.

Kato, Y. (1992). Enzymatic dissociation of plant cell wall polysaccharides. Nippon Jozogakkaishi, 87, 107-115 (in Japanese).

Kato, Y. and Nevins, D.J. (1985). Isolation and identification of $O$-(5- $O$-feruloyl-L-arabinofuranosyl)-( $1 \rightarrow 3)$ - $O$ - $\beta$-D-xylopyranosyl-( $1 \rightarrow 4)$-D-xylopyranose as a component of Zea Shoot cell walls. Carbohydr. Res., 137, 139-150.

Kroon, P.A., Faulds, C.B., Ryden, P. and Williamson, G. (1996) Solubilization of ferulic acid from plant cell wall materials in a model human gut system. Biochem. Soc. Trans., 24, 384S.

Kroon, P.A., Faulds, C.B., Ryden, P., Robertson, J.A. and Williams, G. (1997). Release of covalently bound ferulic acid from fiber in the human colon. J. Agric. Food Chem., 45, 661-667.

Lowry, O.H., Rosebrugh, N.J., Farr, A.L. and Randall, R.J. (1951) Protein measurement with the Folin phenol reagent. J. Biol. Chem. 193, 265-275.

MacKenzie, C.R. and Bilous D. (1988). Ferulic acid esterase activity from Schizophyllum commune. Appl. Environ. Macrobiol., 54, 1170 1173.

Mitsuoka, T. (1995). "Dietary Fiber," ed. by S. Innami and S. Kiriyama. Daiichi-Shuppan, Tokyo, Chapter 8 (in Japanese).

Nelson, N. (1944). A photometric adaptation of the Somogyi method for the determination of glucose. J. Biol. Chem., 153, 375-380.

Nishizawa, C., Ohta, T., Egashira, Y. and Sanada, H. (1997). Differences in enzymatic activities of cecal contents of rats fed on differently processed dietary fiber. Food Sci. Technol. Int. Tokyo, 3 379-383

Ohta, T., Yamasaki, S., Egashira, Y. and Sanada, H. (1994). Antioxidative activity of corn bran hemicellulose fragments. J. Agric. Food Chem., 42, 653-656.

Ohta, T., Semboku, N., Kuchii, A., Egashira, Y. and Sanada, H. (1997). Antioxidant activity of corn bran cell-wall fragments in the LDL oxidation system. J. Agric. Food Chem., 45, 1644-1648.

Shiba, K., Ijitsu, T., Hara, H. and Okada, K. (1992). Preparation and characterization of water-soluble hemicellulose (Arabinoxylan) from wheat bran. J. Jpn. Soc. Food Sci. Technol., 39, 1147-1155.

Shibuya, N. (1984). Phenolic acids and their carbohydrate ester in rice endosperm cell wall. Phytochemistry, 23, 2233-2237.

Somogyi, M. (1952). Notes on sugar determination. J. Biol. Chem., 195, 19-23. 